
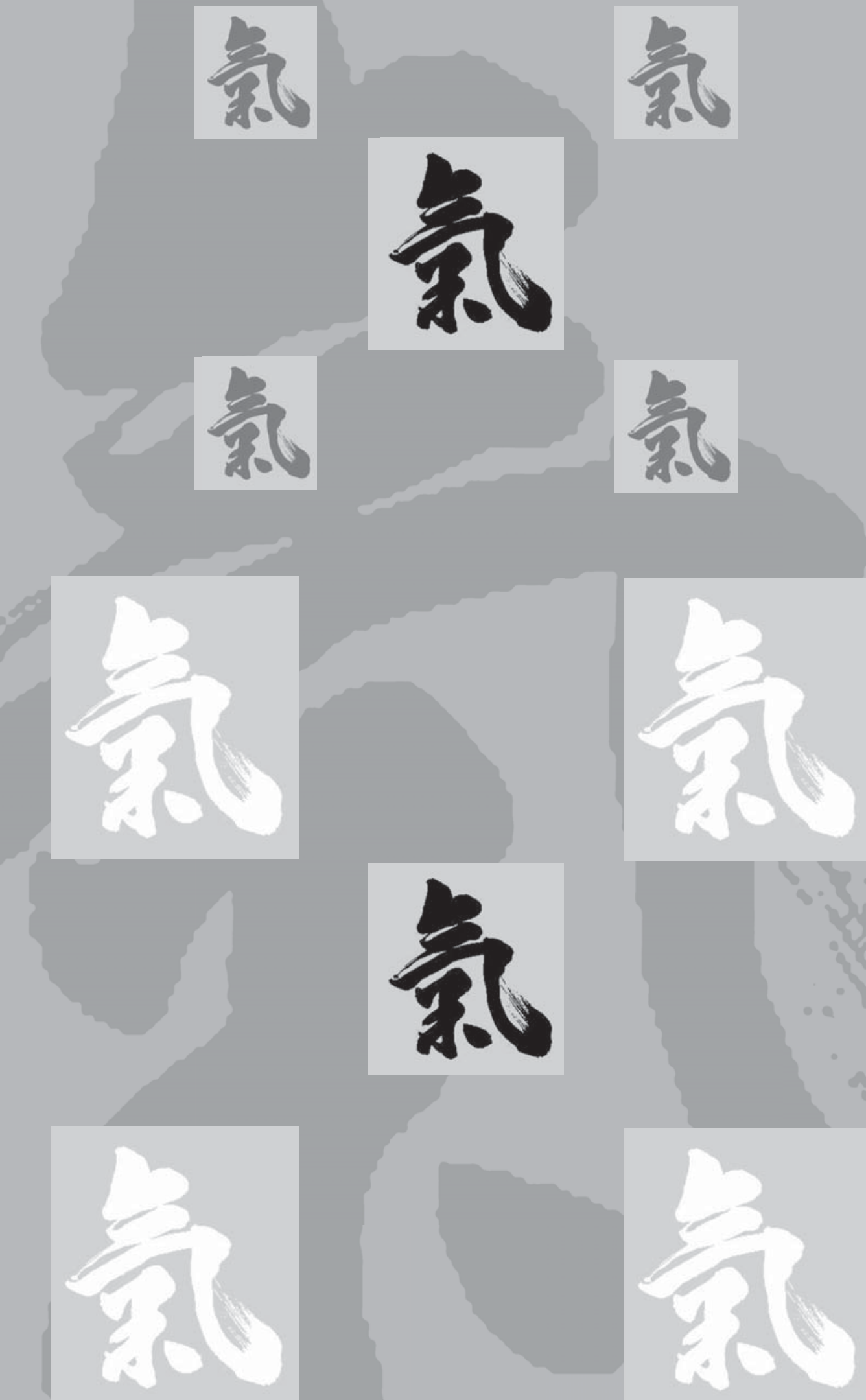


\title{
Ilusiones ópticas en el Aikido
}

\author{
Guillermo Paz-y-Miño C. y Avelina Espinosa
}

\section{Resumen}

Las ilusiones ópticas engañan a la percepción visual de las técnicas de aikido, afectando a varios aspectos de su enseñanza y aprendizaje. Como un truco de magia, las ilusiones en aikido nos hacen creer que estamos viendo algo que no está allí o que no está pasando, generando confusión durante las clases y frustración en los estudiantes y en el instructor. Analizando los componentes de las rutinas del aikido podemos identificar y comprender la procedencia de las ilusiones, y esto puede ayudarnos a mejorar los métodos para comunicar los principios del aiki*. En este trabajo discutimos sobre cómo los estímulos visuales ilusorios distorsionan nuestra interpretación de las formas de rodar y caer, las técnicas de neutralización por parejas, las proyecciones y las armas.

¿Te parece que el borde de esta colchoneta de tatami se asemeja a una línea recta? A mi me parece curva. ¿No es cierto que si prolongas esta línea indefinidamente rodeará la tierra y volverá sobre si misma? Por lo tanto, tiene que ser curva. $\sim$ Koichi Tohei (Reed, 1992:296)

\section{Introducción}

Las ilusiones ópticas son imágenes falsas que engañan a la percepción visual de la forma, el tamaño, el color o el movimiento. Los estímulos visuales ilusorios nos hacen creer que estamos viendo algo que realmente no está allí o que no está pasando. La manera suave y relajada con que un practicante de aikido proyecta a un compañero crea la impresión de que no ha habido ninguna fuerza involucrada en la técnica. Esto es debido a que el ojo humano tiende a no ver la secuencia completa de la técnica, sino únicamente sus componentes más conspicuos (por ejemplo la caída del oponente). La eficiencia en la provocación del desequilibrio, la aplicación de la palanca y el uso de la gravedad (fuerza) son los secretos de esta "magia".

El akido (aiki = armonía, do = sendero, camino de) es rico en ilusiones ópticas. Interfieren en nuestra percepción de una proyección, creando confusión en la clase y frustración en los estudiantes y en los instructores. Aquí discutiremos cómo los estímulos visuales distorsionan nuestra interpretación de un cierto número de rutinas de aikido, incluyendo las formas de rodar y caer, las técnicas de neutralización por parejas, las proyecciones y las armas. Analizando los componentes de las rutinas del aikido podemos identificar y comprender la procedencia de las ilusiones, y esto puede ayudarnos a mejorar los métodos para comunicar los principios del aiki.

\section{* Nota:}

Los "principios del aiki" hacen referencia a la globalidad del arte del aikido, incluyendo las técnicas, los principios biofísicos (acción de la gravedad sobre el cuerpo, fuerza centrípeta, acción de palanca), y la coordinación del cuerpo y la mente (la intención mental va pareja a la acción física).

Fotografías cortesía de A. Espinosa y G. Paz-y-Miño C. 
En este artículo dividimos las ilusiones ópticas del aikido en dos grandes categorías: estáticas y dinámicas. Para comprender la complejidad de las ilusiones más comunes y engañosas del aikido, las dinámicas, debemos abordar en primer lugar las ilusiones estáticas. Recomendamos que todos los estudiantes e instructores sigan esta aproximación.

\section{Ilusiones estáticas}

Las ilusiones estáticas pueden atribuirse a errores en la percepción del contraste, tamaño, orientación o cualquier combinación de estas variables. Más abajo ofrecemos tres ejemplos de ilusiones de:

1) Tamaño-contraste

2) Contraste-orientación, y

3) Tamaño-orientación-contraste.

Un ejemplo de ilusiones de tamaño-contraste se muestra en la Figura 1, donde dos caligrafías idénticas del carácter ki (= energía vital, espíritu de armonía) están rodeadas de cuatro iguales, pero más pequeñas (A) o más grandes (B). Para el observador, parece que la caligrafía rodeada de las otras más pequeñas es más grande que la que está rodeada de los símbolos mayores. Un ejemplo más impresionante de la ilusión de tamaño-contraste de muestra en las figuras C-D. Cuando el ojo humano observa dos imágenes en espejo de un practicante de aikido sosteniendo un bastón de madera (jo), la atención se centra en el bastón. Si el practicante mantiene su brazo doblado (C), esto crea el efecto ilusorio de acortamiento del bastón. En contraste, si su brazo está extendido (D), el efecto es de alargamiento del bastón. La ilusión es el resultado de una mala interpretación de la longitud del bastón (tamaño) debido a la posición del practicante de aikido en relación al bastón y a la flexión o extensión del brazo. Un ejemplo análogo de este tipo de ilusión se muestra en las figuras E-F.

Figura 1

Ilusiones de tamaño-contraste

1-A

1-B
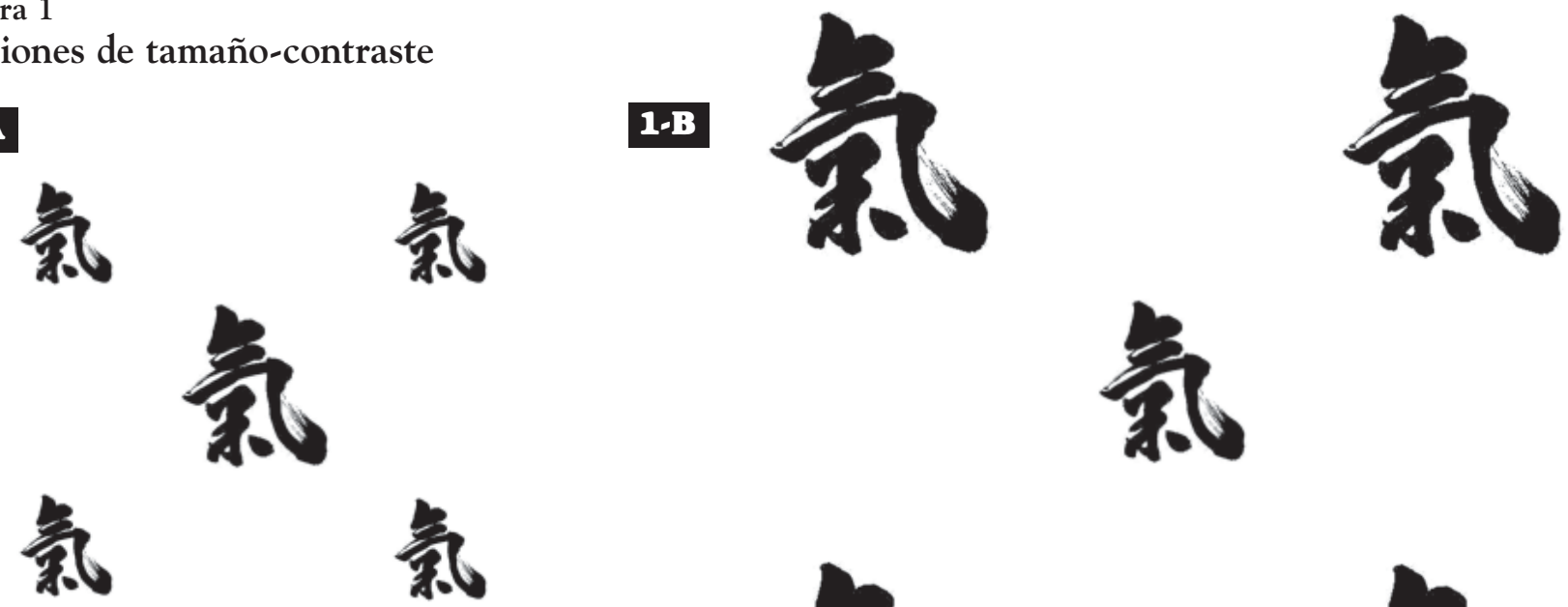

Las dos caligrafías que están rodeadas por cuatro caracteres más pequeños $(\mathrm{A})$ o más grandes $(\mathrm{B})$ son idénticas.
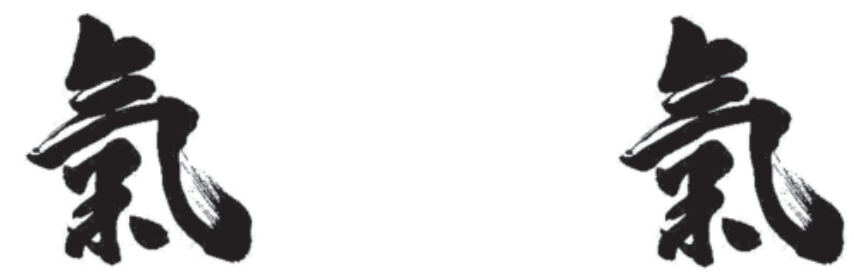

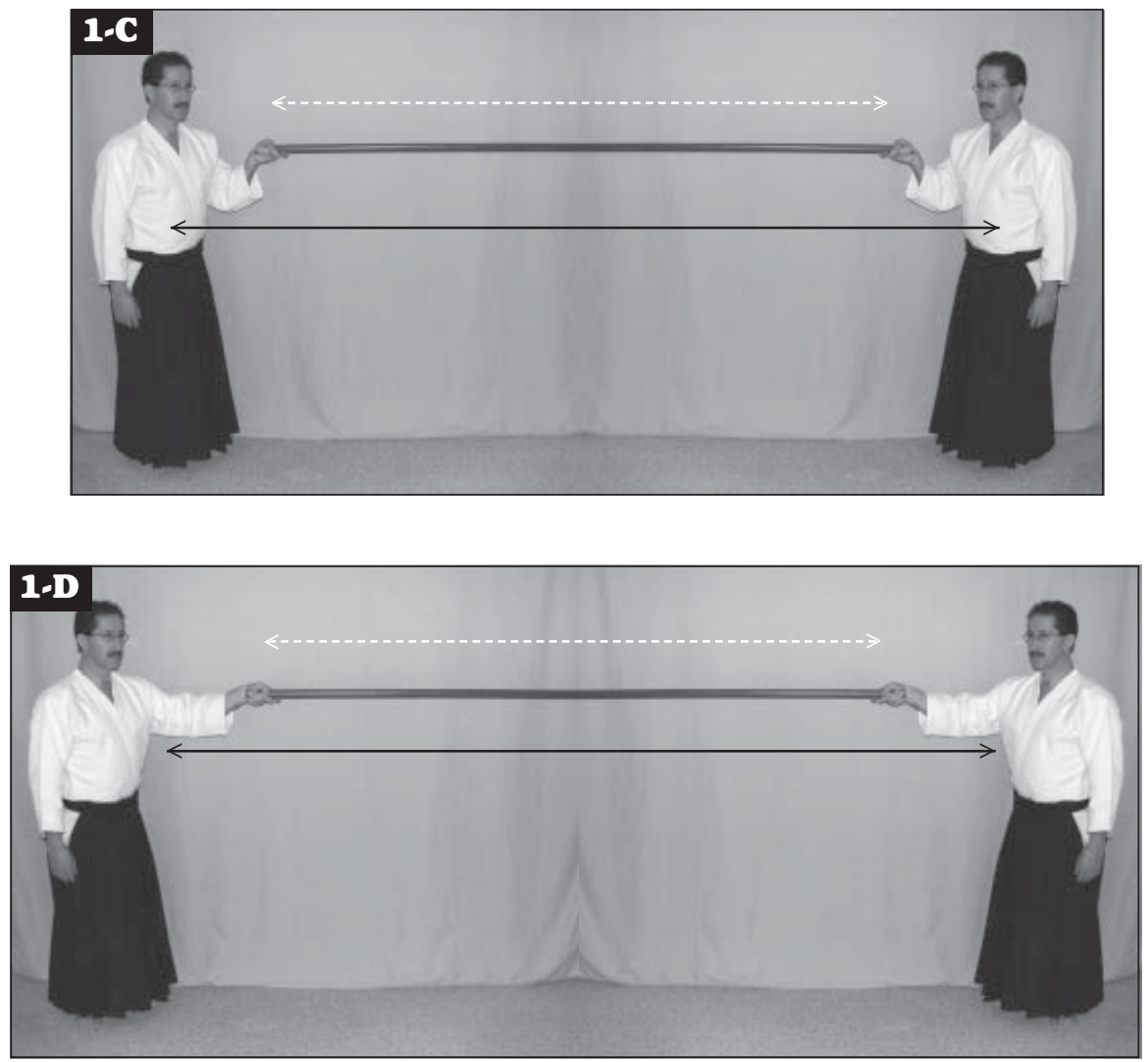

La longitud del bastón que sostiene el practicante de aikido en las dos imágenes en espejo (C-D) es la misma (línea punteada), pero la posición del practicante respecto al bastón es diferente (línea continua) como consecuencia de haber flexionado o extendido su brazo.

La demostración es simple pero potente (E-F): cuando el practicante sostiene el bastón con sus brazos cerca del cuerpo, el bastón parece más corto que cuando mantiene los brazos abiertos. Aunque la longitud del bastón nunca cambia (línea punteada), la posición de sus brazos sí lo hace (línea continua). En todos estos casos la escala y distribución de los elementos del entorno circundante interfiere con la percepción del tamaño.
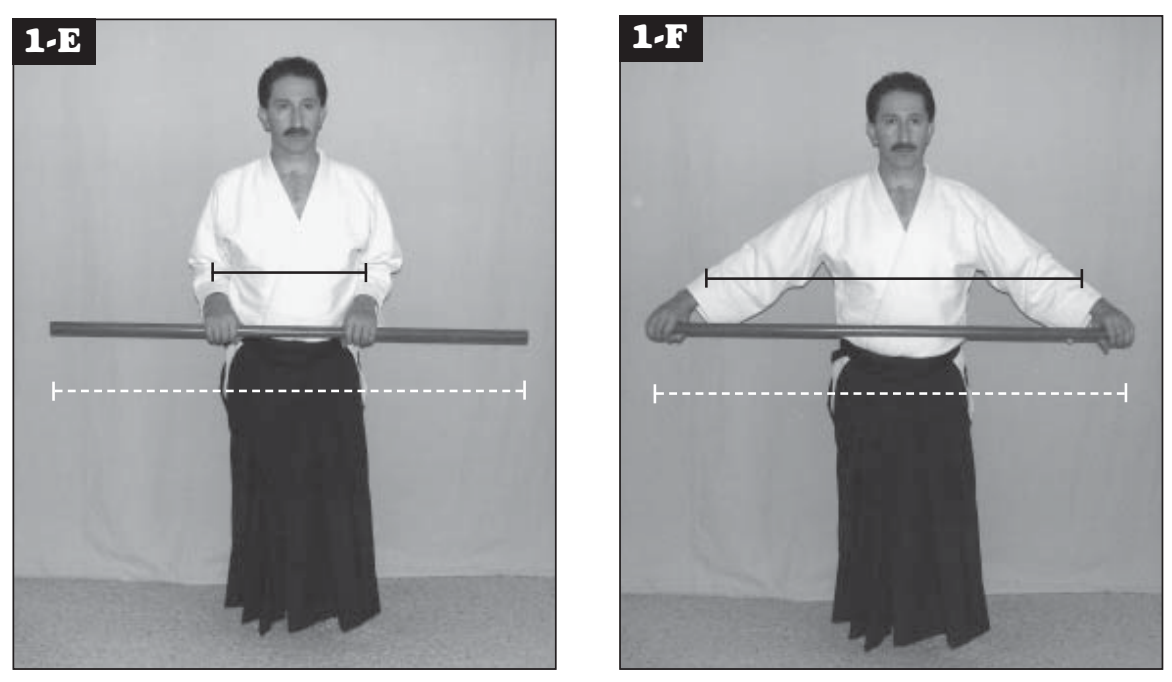
Un ejemplo de ilusión de orientación-contraste se muestra en la Figura 2. En este caso se han colocado varios bastones de madera (jo), equidistantes y paralelos unos con otros, mientras que algunos cuchillos de madera los cruzan en direcciones opuestas. Este contraste en la orientación de las líneas crea la ilusión de que los bastones confluyen cerca de sus extremos.

La Figura 3 muestra ejemplos de ilusiones de tamaño-orientación-contraste. Las dos campanas suzu (A) (usadas para los vigorosos cantos del aikido) son idénticas. Sin embargo, la orientación de las líneas en el fondo hacer que la campana de la izquierda parezca más grande que la campana de la derecha. Las tres fotografías de un practicante de aikido de pie y sosteniendo un bastón (B) son también idénticas, pero el fondo crea la ilusión de que la que está más lejos es la más grande. Finalmente, la disposición de dos espadas de madera (bokkens) en medio de dos bastones divergentes da la impresión de que la espada que está más arriba es más grande que la espada que está más abajo (C).

\section{Figura 2}

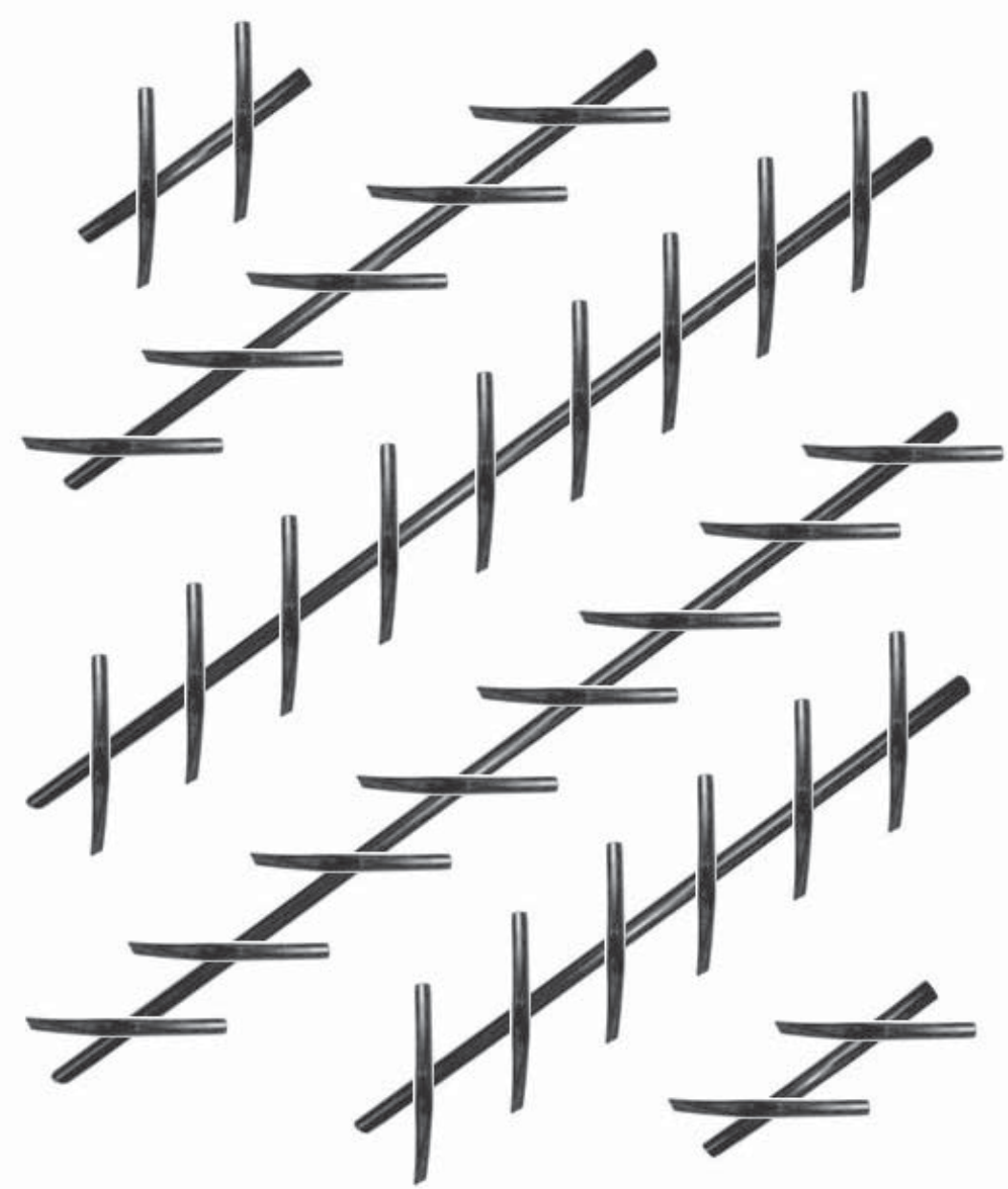

La orientación contraria de los cuchillos de madera (tanto) en relación a los bastones crea la ilusión de que los bastones confluyen cerca de sus extremos. 
Figura 3

Ilusiones de tamaño-orientación-contraste

3-A
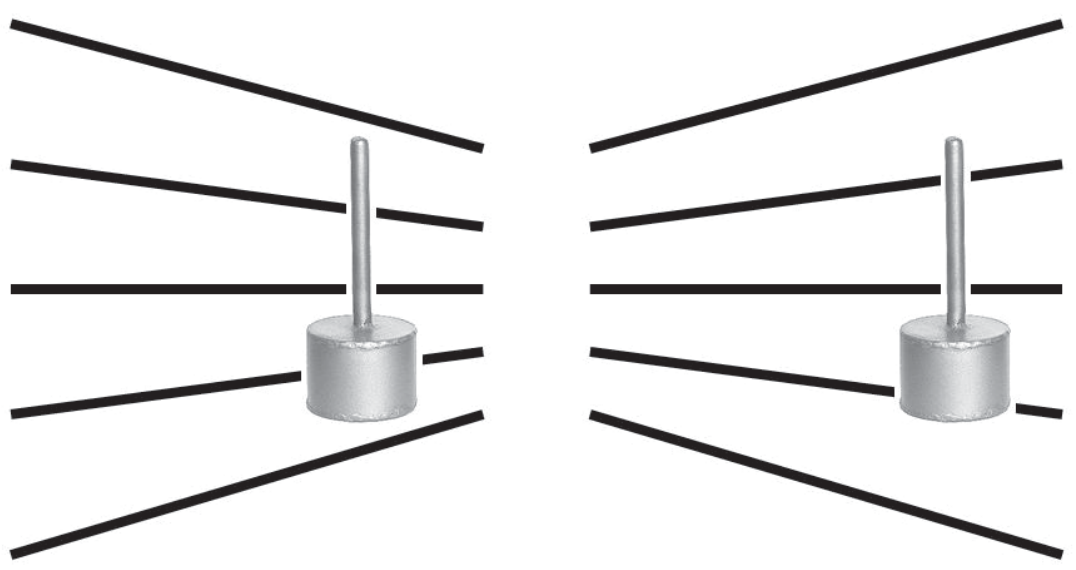

La orientación y disposición de las líneas en el fondo da la impresión que las campanas suzu (A) y las fotografías del practicante de aikido (B) son de tamaño diferente.

\section{3-C}

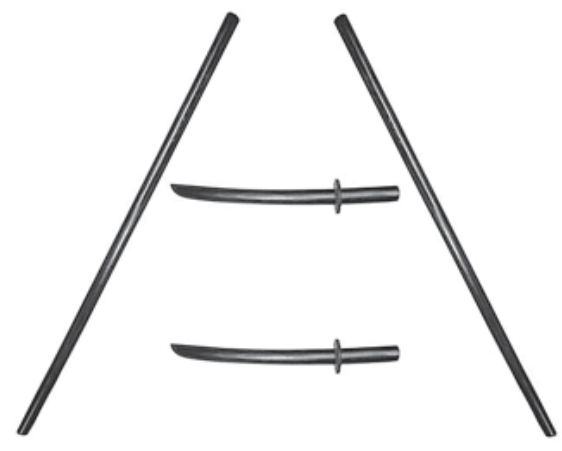

Un efecto ilusorio similar se manifiesta cuando dos espadas de madera se colocan en el hueco formado por dos bastones divergentes $(\mathrm{C})$. 


\section{Ilusiones dinámicas}

Las ilusiones ópticas dinámicas se producen también por errores en la percepción del contraste, el tamaño o la orientación, pero estos estímulos visuales ilusorios emergen solamente cuando estas variables interactúan en movimiento. Algunas ilusiones son, por ejemplo, la apariencia de movimiento de un practicante que está estático, como resultado del movimiento de otros que están a su alrededor. Existen escenarios en los cuales dos o más practicantes se mueven a velocidades semejantes, y, sin embargo, sus velocidades pueden ser percibidas como diferentes. Más aún, si dos practicantes se mueven a la misma velocidad, puede parecer que aquel que ejecuta la técnica permanece quieto mientras que su compañero se está moviendo. Las ilusiones dinámicas provienen de la interacción de los patrones cinéticos del practicante (únicos para la anatomía humana), con su velocidad relativa de movimientos mientras ejecuta una técnica, y con las características del medio (contraste, tamaño y orientación de objetos; luz, profundidad y textura del fondo, e incluso los sonidos y/o ruidos pueden interferir con la percepción del movimiento).

Las técnicas de aikido incluyen una compleja combinación de movimientos aparentemente independientes en un entorno tridimensional. El instructor a menudo ejecuta con exactitud todos estos componentes "independientes" y los mezcla en movimientos armoniosos. Puesto que el ojo humano captura los elementos más relevantes de esta mezcla, el estudiante pasa por alto los detalles inintencionadamente. Su percepción visual de la demostración del profesor es incompleta e ilusoria. El estudiante y el profesor, a menudo, no son conscientes de este fenómeno. Puesto que la ilusión no es conceptual, sino perceptiva, saber que el efecto es ilusorio no disminuye la fuerza de la ilusión. En poco tiempo el estudiante y el profesor desarrollan un lazo de feedback negativo: el joven practicante continúa imitando únicamente los elementos más importantes de la rutina, mientras que el instructor lucha por comunicar los detalles importantes dentro de la técnica global. La ilusión corrompe la correcta comprensión de esos detalles porque, en muchos casos, el estudiante ni siquiera puede verlos. Al final, el estudiante y el instructor acuerdan que sólo un entrenamiento a largo plazo y un trabajo arduo físicamente solventarán el problema.

Creemos que esta dificultad puede ser minimizada, no luchando ciegamente contra la fuerza de la ilusión (por ejemplo, por medio de un entrenamiento físico a largo plazo hasta que el cuerpo, no la mente, encuentre la respuesta al problema), sino más bien reconociendo conscientemente su existencia. Aquí ofrecemos algunos consejos que pueden ayudarle a lograr esta meta.

1. Admita que todas las técnicas de aikido incluyen una o más ilusiones visuales.

2. Acepte que cuando se ve una técnica las ilusiones emergen cuando los movimientos del "punto central" o del centro del equilibrio corporal (situado aproximadamente a dos pulgadas [ $5 \mathrm{~cm}$.] por debajo del ombligo), interactúan con los movimientos de las extremidades superiores (los "detalles" a los que hacíamos referencia). Si el cuerpo se mueve hacia arriba/abajo (por flexión de rodillas), rota (por un giro), o se desplaza (por dar un paso), los brazos también se moverán en estas direcciones. En términos físicos esto es cierto incluso si el practicante nunca mueve las articulaciones de sus brazos. ¿Por qué? ¡Porque el cuerpo no puede moverse sin que le acompañen sus extremidades! Consecuentemente, los sutiles movimientos de los brazos, que son característicos de las artes del aikido, parecerán mayores a los ojos del observador, puesto que son enfatizados por los movimientos de su punto central. El observador tenderá a exagerar y/o a distorsionar este o cualquier otro movimiento relacionado con los movimientos del punto central. 


\section{Figura 4}

Giro hacia delante desde la postura sentada formal (seiza)
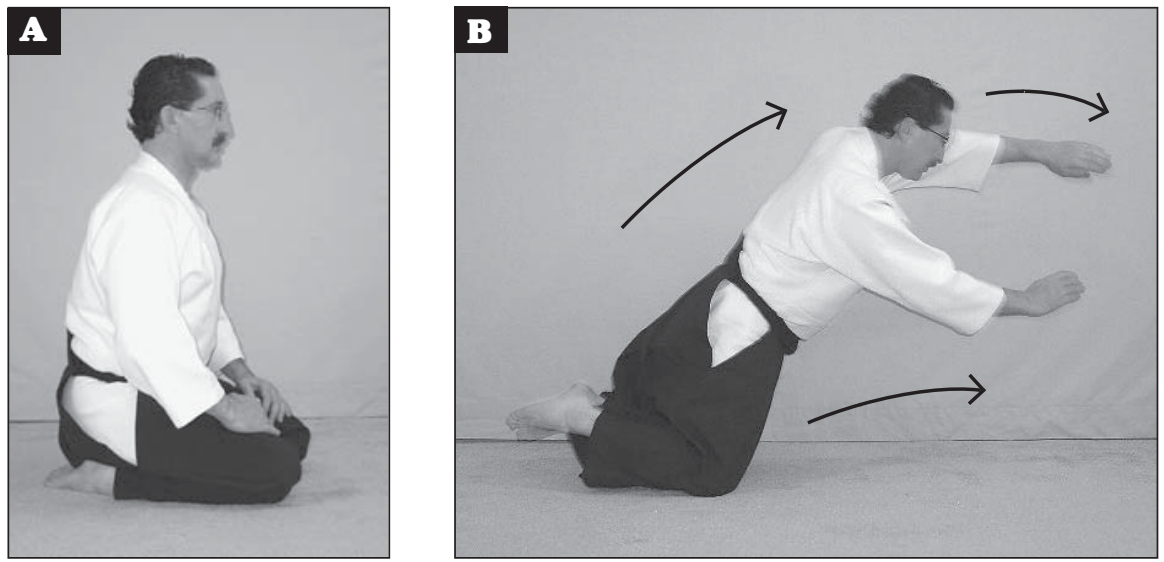

Posición inicial: postura sentada formal (A). Levante su cuerpo hacia arriba y "láncese" en un giro hacia delante (B). Continúe rodando (C-D).

Disminuya su velocidad y prepárese para la "forma de caminar de rodillas" (E-F). La ilusión óptica hace creer al observador que el practicante flexiona rápidamente el cuerpo para realizar el giro (incorrecto B) e intenta levantarse tan pronto como su espalda toca la colchoneta (incorrecto C).

La flexión temprana del cuerpo compromete el conjunto de la técnica, impidiendo que el practicante finalice la caída (incorrecto E). El giro debe ser grande, extenso y hacia delante, $y$, sin embargo, el estudiante lo ve pequeño, corto y contraído.

\section{D}
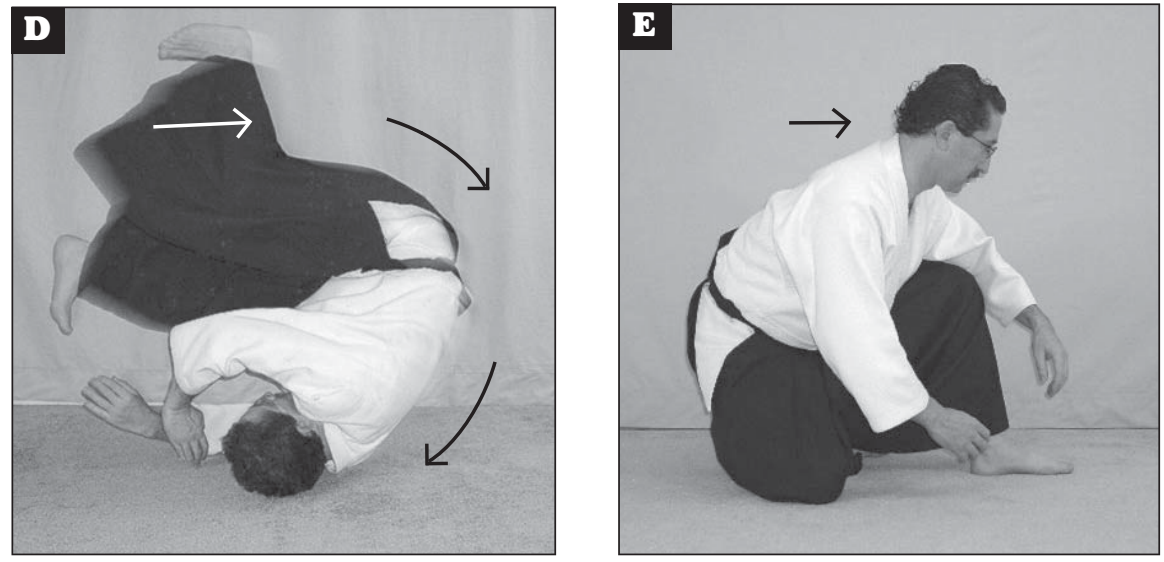
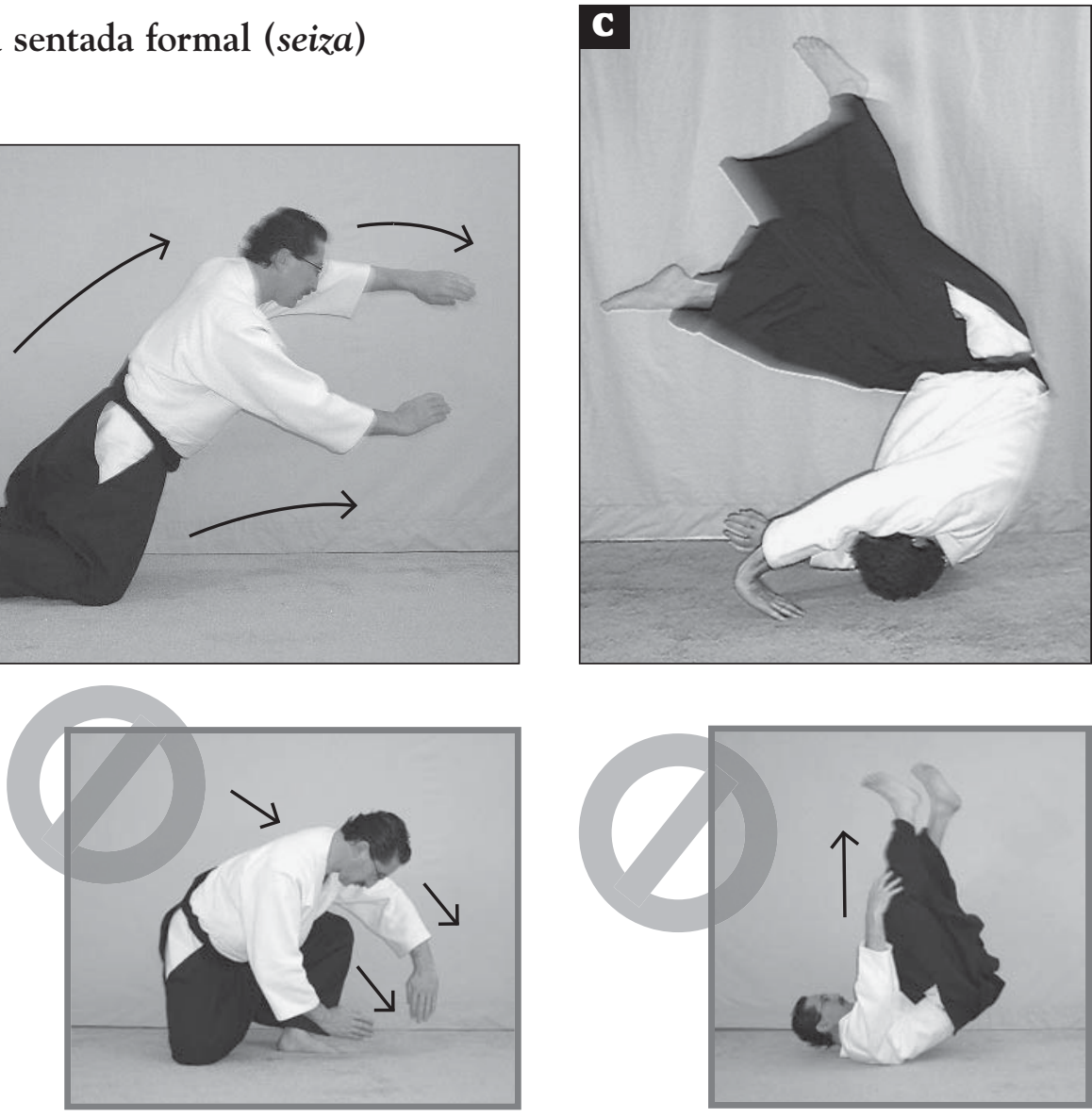

Incorrecto - B

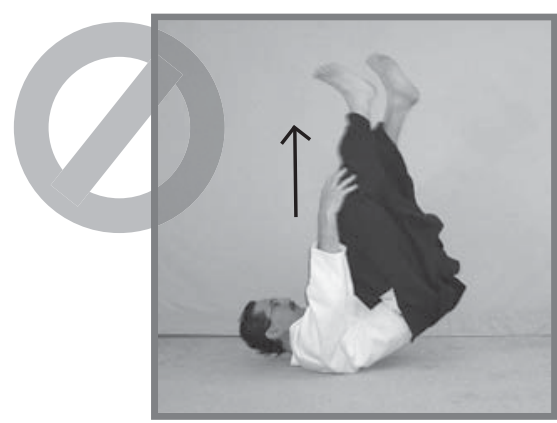

Incorrecto - C

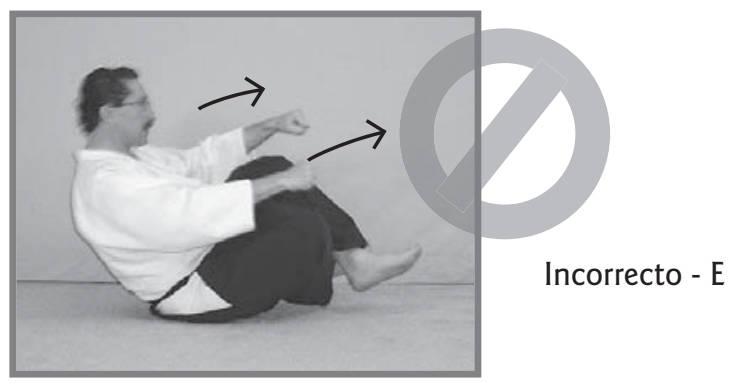

$\mathbf{F}$

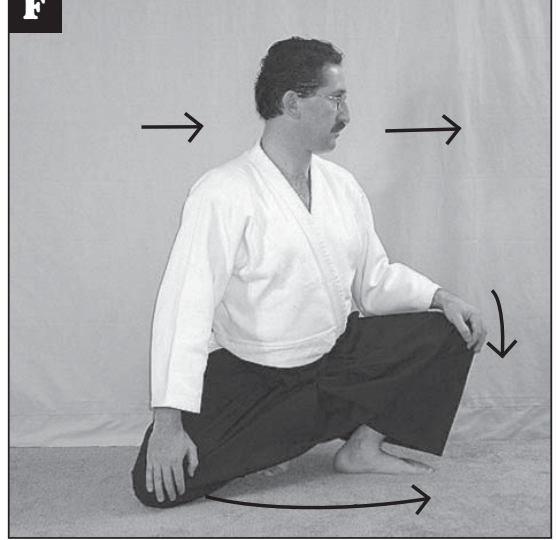


3. Asegúrese de comprender los movimientos del punto central y de los movimientos de los miembros superiores por separado antes de tratar de unirlos.

4. Sea crítico con usted mismo y permita que otros le corrijan. Ellos también deberían estar prevenidos de la existencia potencial de ilusiones.

5. Sea comprensivo con usted mismo y con los demás. Recuerde que, al igual que si viese un truco de magia repetido muchas veces, conocer que el efecto visual es ilusorio no disminuye la fuerza de la ilusión.

A continuación ofrecemos algunos ejemplos de cómo las ilusiones dinámicas distorsionan nuestra interpretación de diversas artes del aikido. Cada figura incluye una descripción detallada de cómo realizar las rutinas, indicando la ejecución "incorrecta" de una técnica o de alguna de sus partes.

\section{Figura 5}

\section{Bloqueo con las tres palmas hacia arriba}
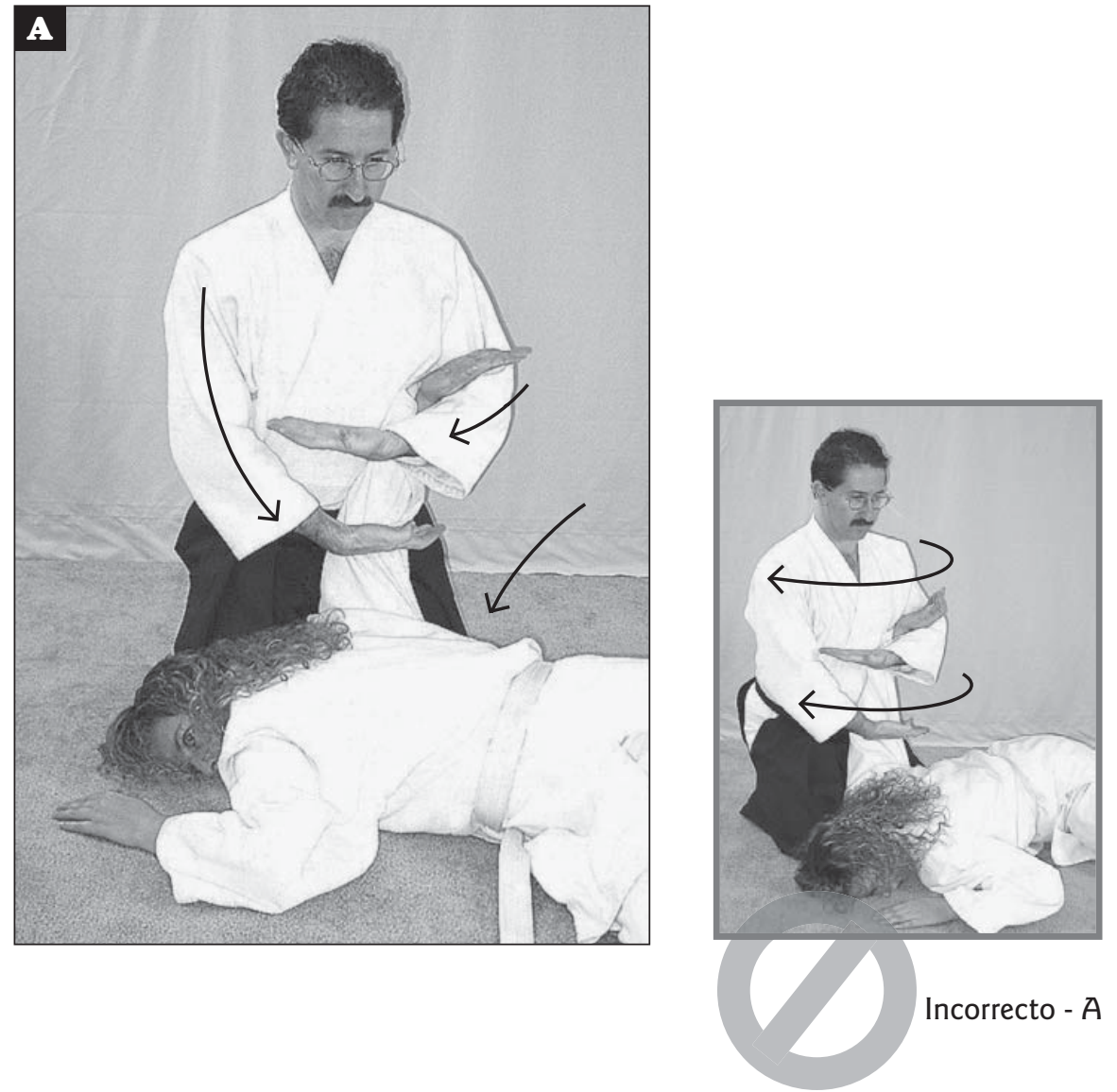

Este bloqueo se basa en trayectorias angulares complejas aplicadas sobre el brazo: una en la dirección de cada una de las manos del practicante (hacia abajo y hacia dentro), y otra en la dirección del hombro del atacante (observe las tres flechas). La ilusión óptica confunde la interpretación de la técnica, haciendo que el observador crea que el practicante está girando su torso hacia la derecha (incorrecto A), lo cual realmente libera al atacante o, incluso peor, lesiona su hombro en vez de simplemente restringir su movimiento. 
Figura 6

\section{Bloqueo de muñeca}

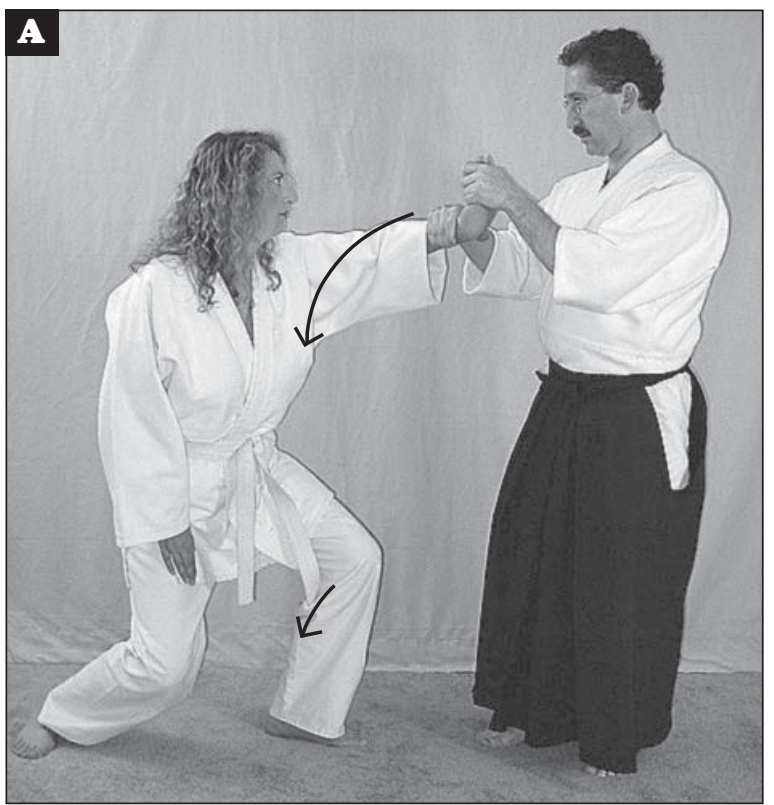

Incorrecto - $A$

Mantenga los dedos del atacante apuntando hacia arriba y doble la muñeca del atacante hacia su punto central (A-B). La trayectoria de la técnica, que conecta la muñeca con el codo, hombro y punto central, obliga al atacante a arrodillarse. Para el observador, parece como si el practicante estuviese levantando el brazo del atacante y proyectándolo sobre la cabeza (incorrecto A), lo cual lleva a una pérdida de control del bloqueo (incorrecto B) y del conjunto de la técnica.
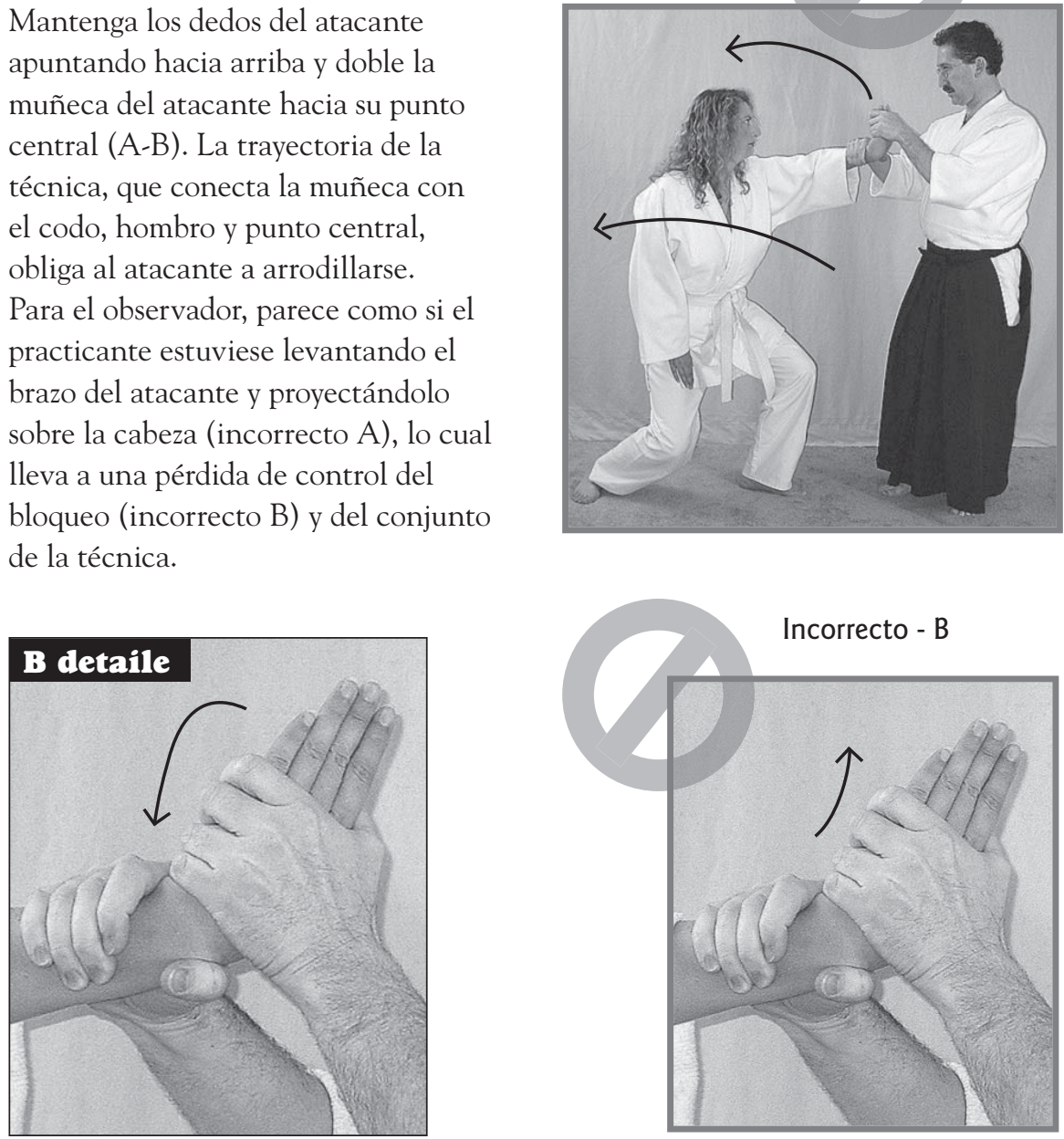

Incorrecto - B

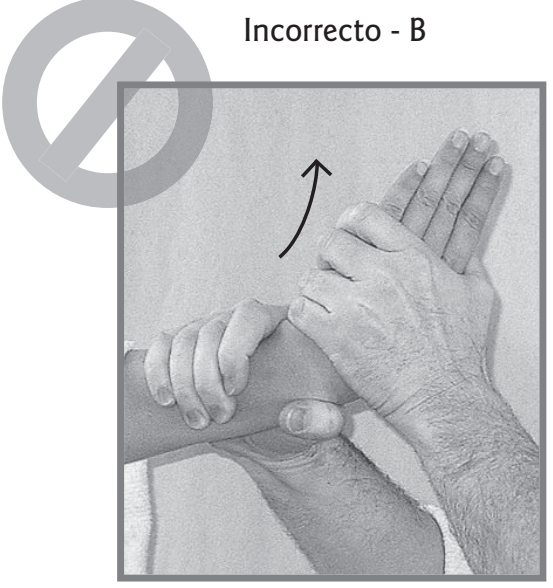


Figura 7

Proyección lateral desde la postura sentada formal
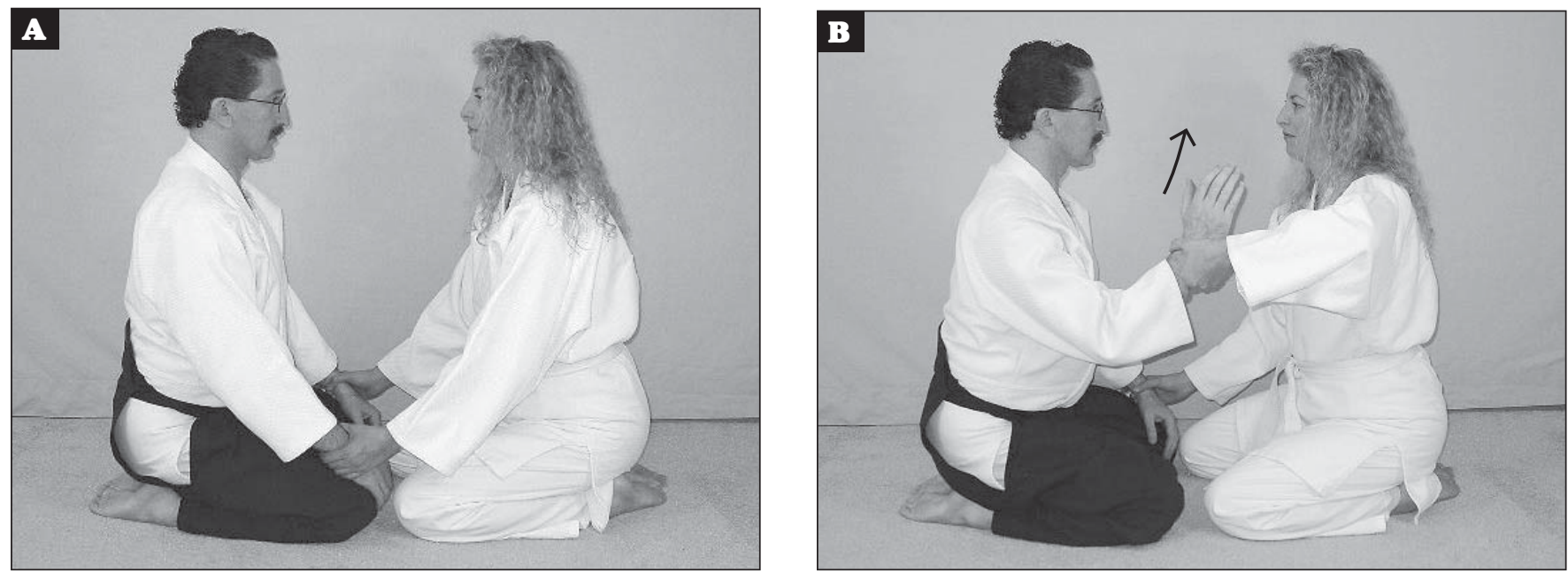

El atacante (a la derecha) realiza un doble agarre a las dos muñecas (A). El defensor (izquierda) mueve su mano derecha hacia arriba, apuntando con sus dedos hacia arriba (B). La mano izquierda del defensor refleja el movimiento inicial de la mano derecha y después conduce al atacante hacia fuera y atrás, proyectándolo diagonalmente hacia atrás (C). La rodilla derecha del defensor se levanta y también se gira la muñeca del atacante con la mano derecha al mismo tiempo que la mano izquierda dirige la dirección del movimiento. El atacante se gira completamente sobre su cadera y realiza una caída (D).

La ilusión óptica en esta técnica es fuerte. Parece como si el defensor empujase hacia atrás al atacante (incorrecto B) y tratase de caminar sobre él (incorrecto C). El éxito en la ejecución de esta técnica se basa en la rotación del cuerpo del atacante, la cual se realiza hacia abajo y muy cerca de la rodilla derecha del defensor.
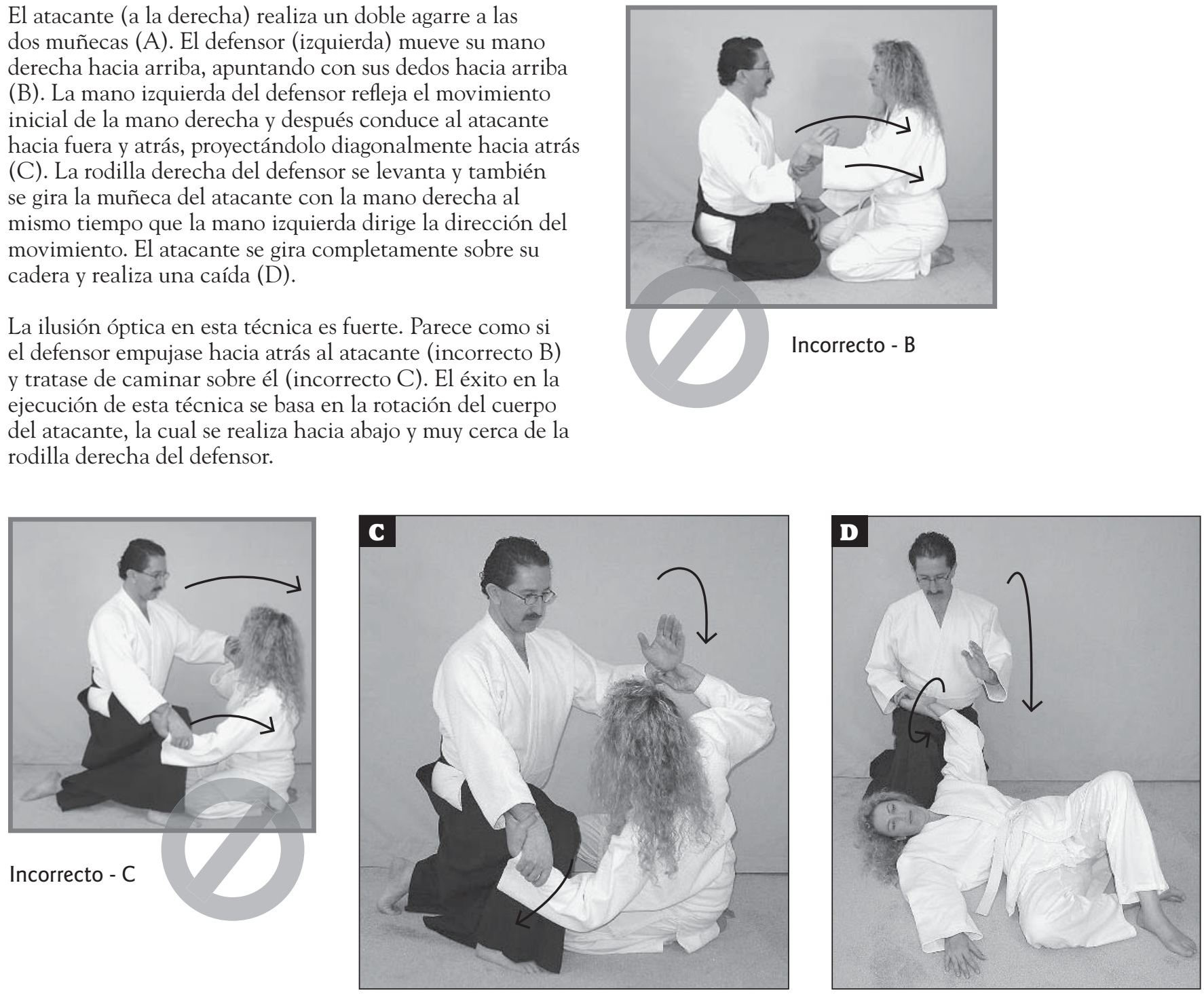


\section{Figura 8}

\section{Proyección en forma de arpón}
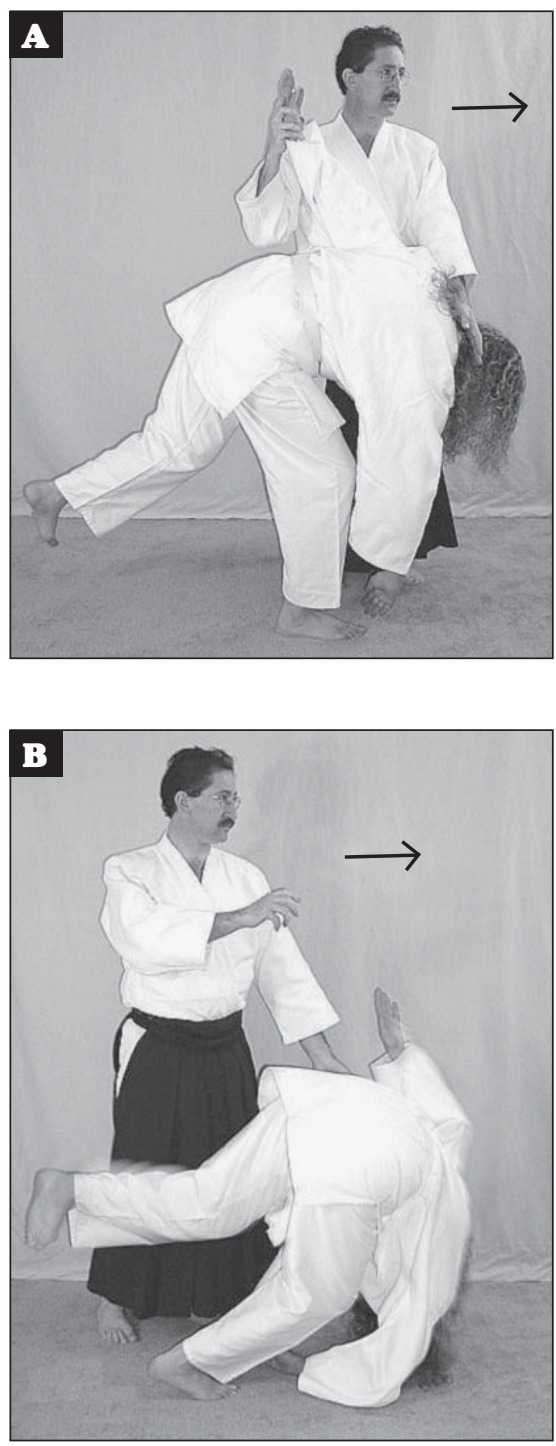

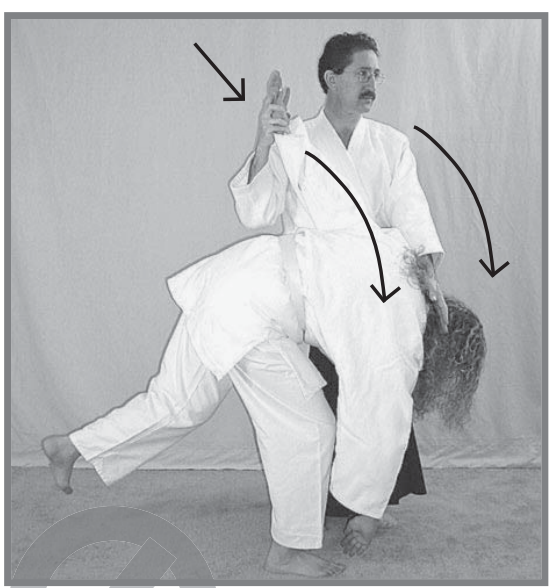

Incorrecto - A

El practicante (de pie) conduce al atacante hacia una posición inclinada (A) antes de proyectarle mediante un giro hacia delante (B) y una caída (C). La proyección es suave y paralela respecto al suelo. Sin embargo, la ilusión óptica hace que parezca como una ruda proyección hacia abajo, contra el tapiz, generada principalmente por la fuerza del practicante que empuja con su brazo al atacante (incorrecto A).

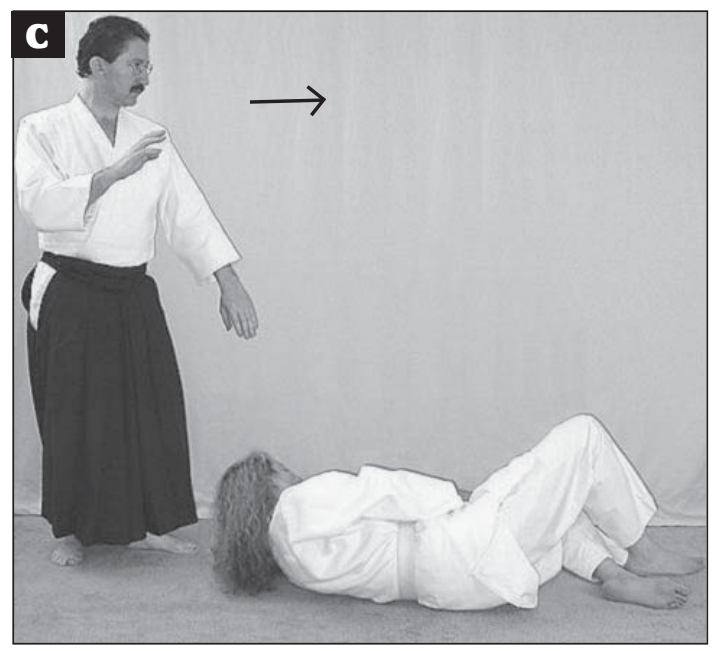

La impresionante potencia de esta técnica se genera por el movimiento del conjunto del cuerpo del practicante (no su brazo), ya que da un paso hacia delante mientras sigue al atacante en la misma dirección. 
Figura 9

Flexión de muñeca y proyección por el hombro
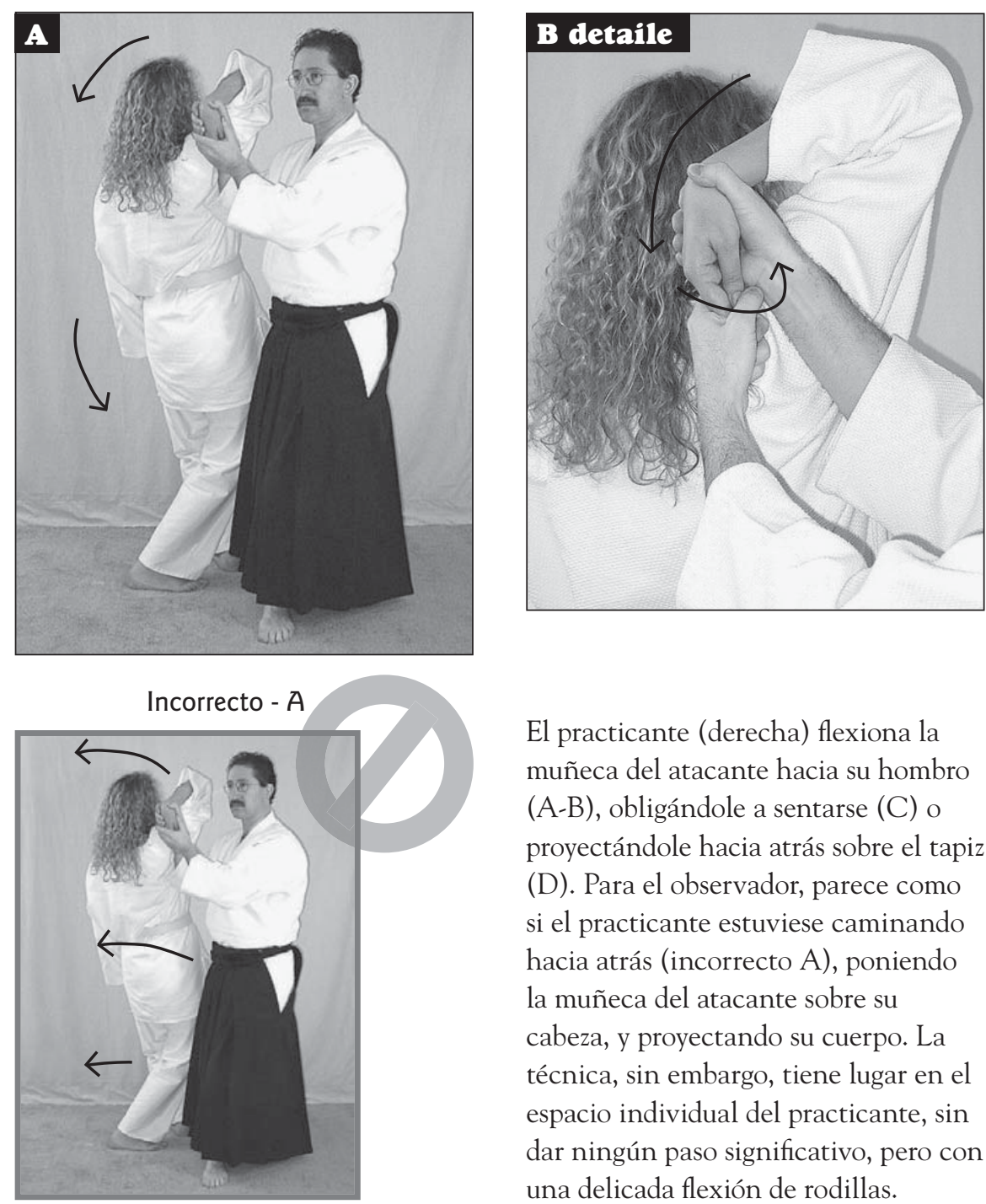

El practicante (derecha) flexiona la muñeca del atacante hacia su hombro (A-B), obligándole a sentarse (C) o proyectándole hacia atrás sobre el tapiz (D). Para el observador, parece como si el practicante estuviese caminando hacia atrás (incorrecto $\mathrm{A}$ ), poniendo la muñeca del atacante sobre su cabeza, y proyectando su cuerpo. La técnica, sin embargo, tiene lugar en el espacio individual del practicante, sin dar ningún paso significativo, pero con una delicada flexión de rodillas.
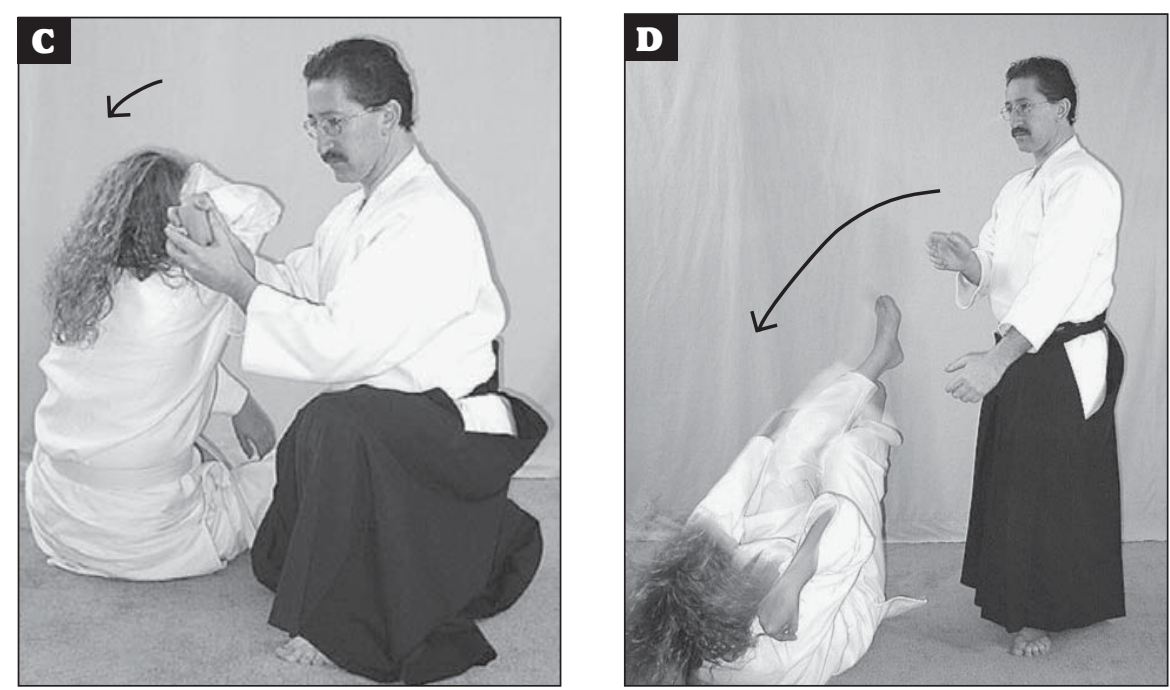
Figura 10

Neutralización de un ataque directo con un cuchillo (tanto)
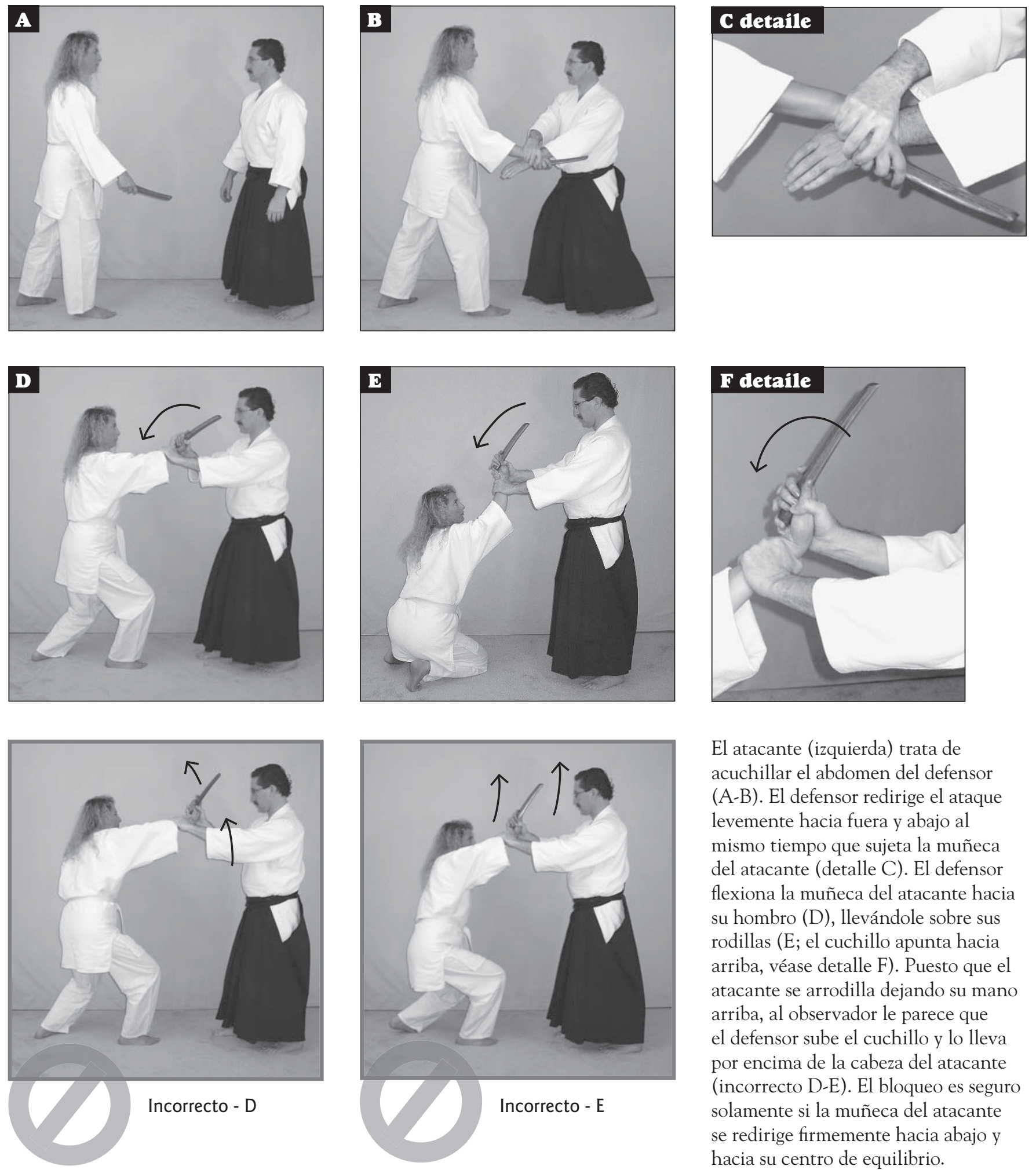

El atacante (izquierda) trata de acuchillar el abdomen del defensor (A-B). El defensor redirige el ataque levemente hacia fuera y abajo al mismo tiempo que sujeta la muñeca del atacante (detalle C). El defensor flexiona la muñeca del atacante hacia su hombro (D), llevándole sobre sus rodillas (E; el cuchillo apunta hacia arriba, véase detalle F). Puesto que el atacante se arrodilla dejando su mano arriba, al observador le parece que el defensor sube el cuchillo y lo lleva por encima de la cabeza del atacante (incorrecto D-E). El bloqueo es seguro solamente si la muñeca del atacante se redirige firmemente hacia abajo y hacia su centro de equilibrio. 


\section{Figura 11}

Corte con un cuchillo (tanto), espada (bokken) y bastón (jo)

El corte vertical con una mano es idéntico al corte con un cuchillo, espada o bastón (A-B-C). Puesto que el arma es una extensión del cuerpo, los ajustes a su longitud son importantes, pero no se debe comprometer la corrección de los movimientos.
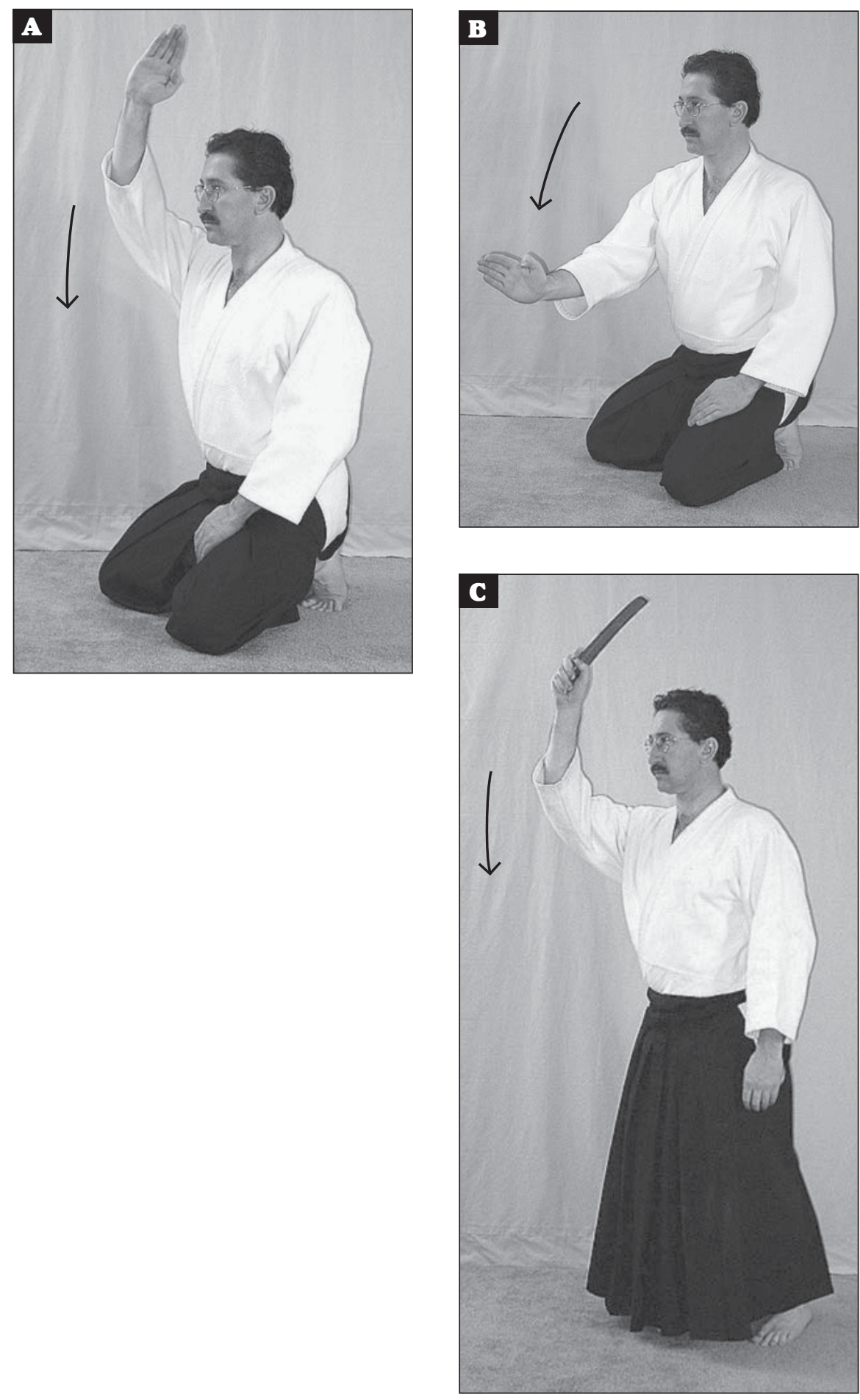


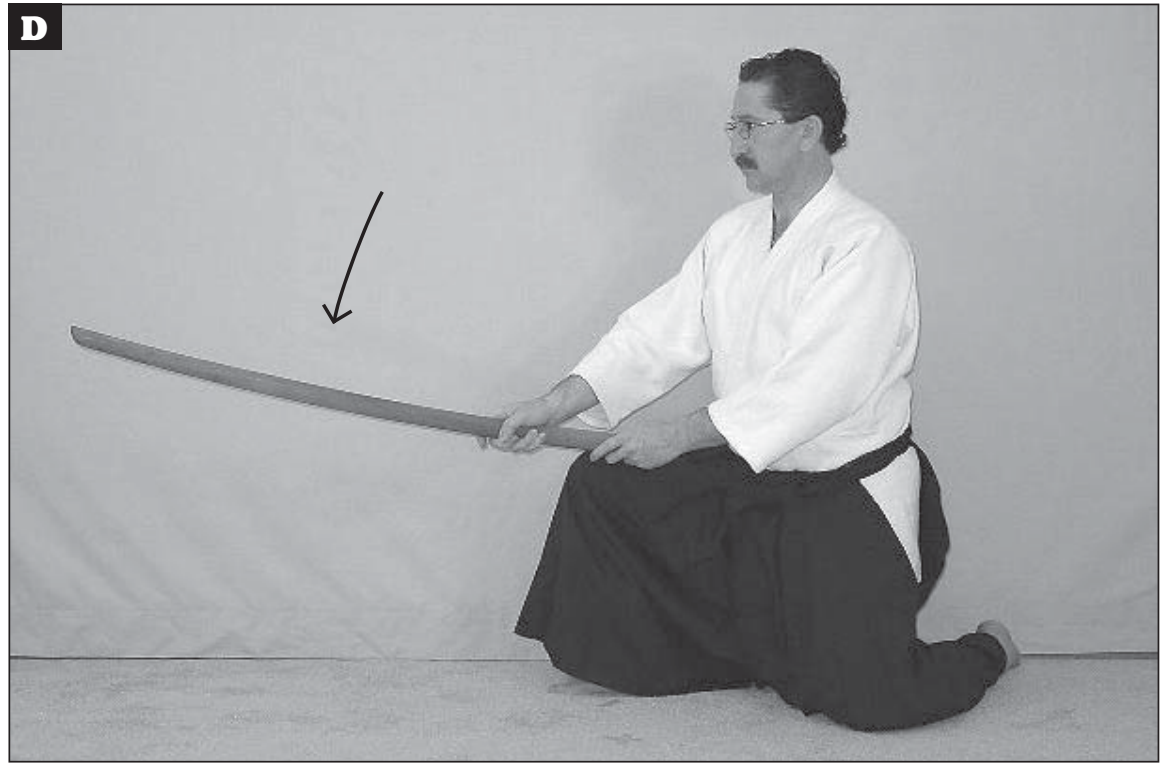

Ya que el practicante de aikido fija su vista en el horizonte mientras corta con un arma (D-E), al observador le parece que está lanzando el arma hacia delante tratando de alcanzar un objetivo distante (incorrecto D-E). En realidad, el corte se realiza cerca del cuerpo del practicante y se dirige hacia el suelo aunque el vector e intención visual converjan en el horizonte.

\section{$\mathbf{5}$}

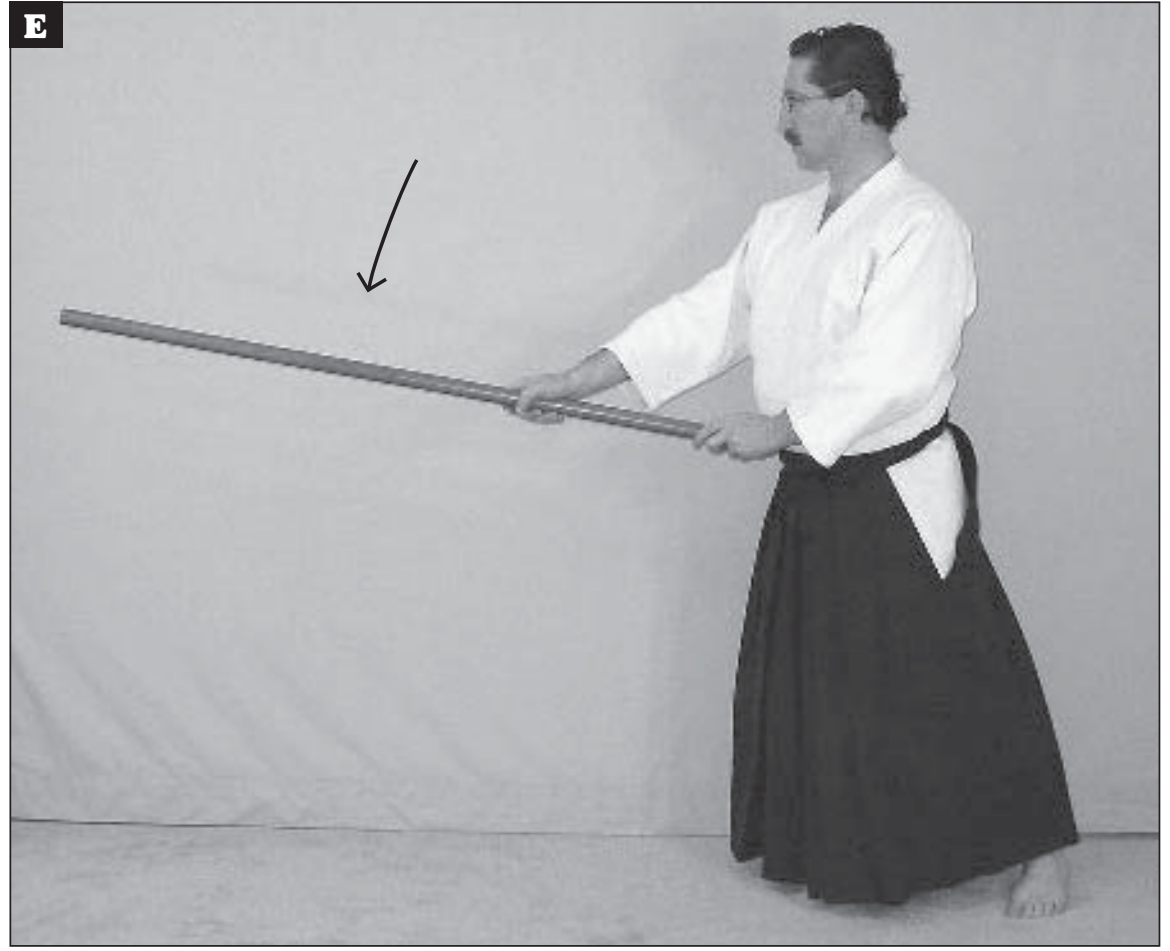

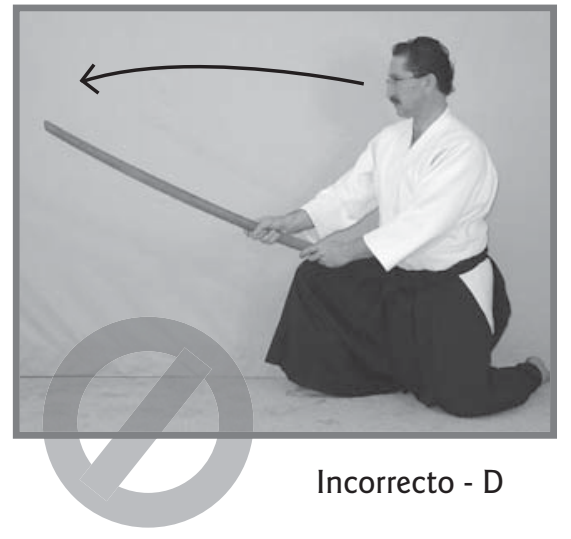

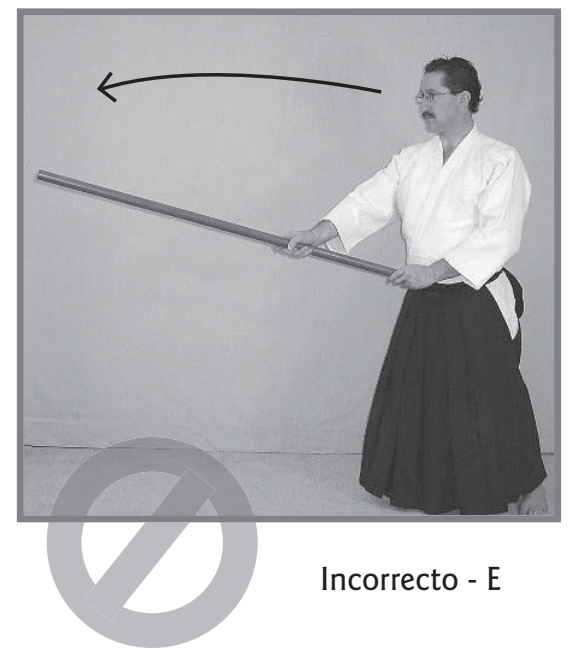




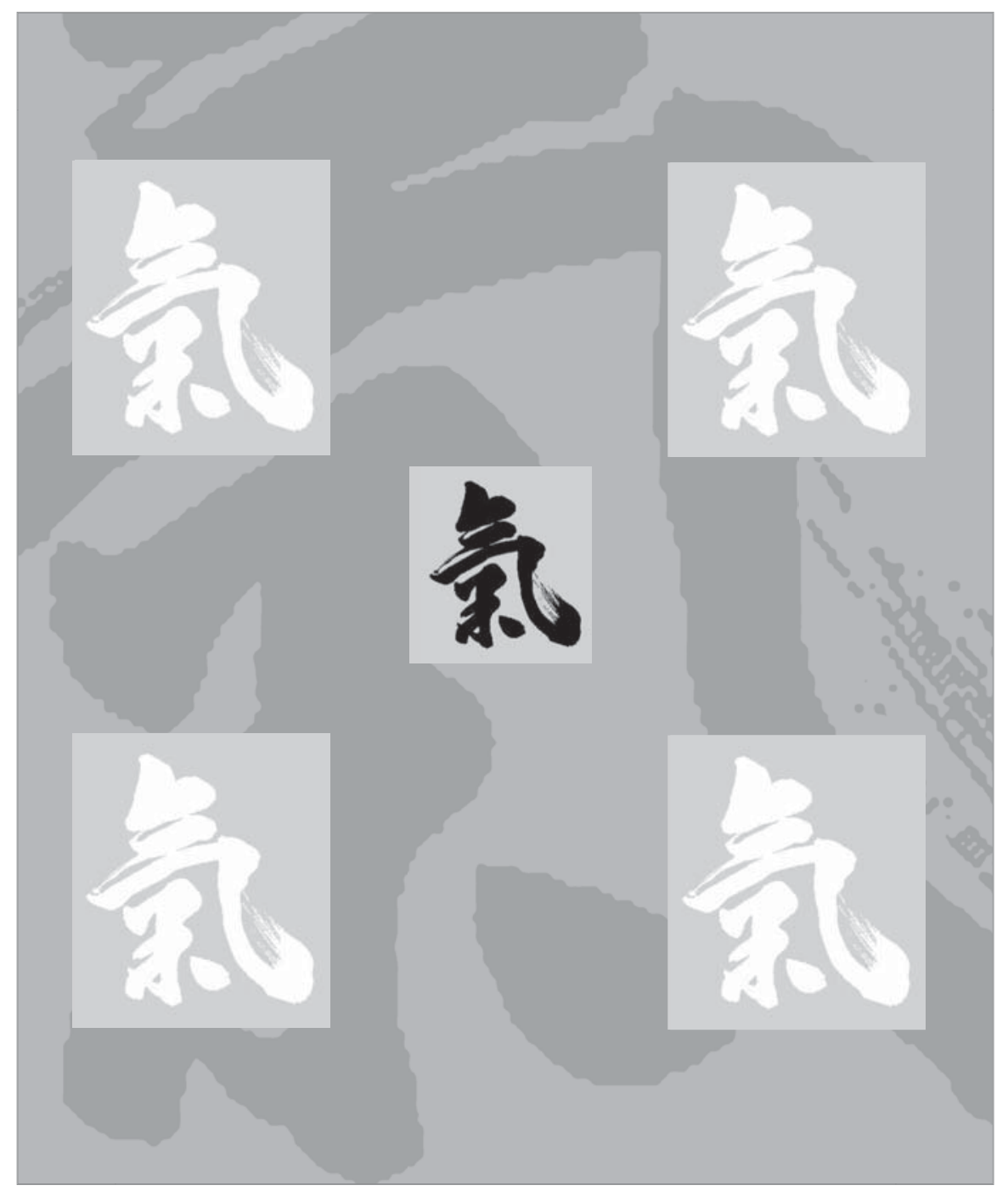

\section{Comentarios finales}

Para agilizar el proceso de aprendizaje, la magia del aikido debe ser mostrada a todos los estudiantes. De este modo, estos comprenderán de un modo crítico y analítico la lógica del aikido. También serán eficientes e independientes en su desarrollo. Puesto que los errores en la percepción visual son universales para el ojo humano, las ilusiones ópticas no son exclusivas de las artes del aiki. Como el aikido, otras disciplinas marciales basadas en lanzamientos y proyecciones pueden esconder ilusiones ópticas en sus formas. Los lanzamientos y las proyecciones están basados en trayectorias equiangulares (espirales), con rotaciones amplias y continuas del centro de gravedad. Combinadas con los movimientos de los brazos, pueden crear ilusiones. Las artes de golpeo, en contraste, enfatizan las rotaciones del centro de equilibrio y los golpes lineales, comunicando menos información confusa al ojo humano (lineal, por supuesto, en términos relativos). Con este artículo esperamos haber generado una concienciación sobre algunas dificultades intrínsecas en el aprendizaje y la enseñanza de los principios del aikido, y hemos sugerido algunas estrategias para lidiar con ellas. 


\section{Bibliografía}

Carlson, T., Schrater, P. \& He, S. (2006). Floating square illusion: perceptual uncoupling of static and dynamic objects in motion. Journal of

Vision 6, 132-144.

Curtis, C. (2001). Ki-Aikido on Maui, 3rd Ed. Maui, Hawaii: MAKS Publications.

Gillam, B. (1980). Geometrical illusions, pp. 87-94. In Scientific American The Mind's Eye. New York: W. H. Freeman and Company.

Goodale, M. \& Humphrey, G. (1998). The objects of action and perception. Cognition, 67, 181-207.

Gregory, R. (1997). Knowledge in perception and illusion. Philosophical Transactions of the Royal Society London B, 352, 1121-1128.

Maruyama, K. (1984). Aikido with ki. Tokyo: Ki No Kenkyukai Headquarters.

Paz-y-Miño C., G. \& Espinosa, A. (2002). Dichotomous keys to fundamental attacks and defenses in aikido. Journal of Asian Martial Arts, 11(1), 8-27.

Paz-y-Miño C., G. \& Espinosa, A. (2002). Aikido: the art of the dynamic equiangular spiral. Journal of Asian Martial Arts, 11(4), 8-29.

Paz-y-Miño C., G. \& Espinosa, A. (2004). The rhythm of aikido: Part I. Journal of Asian Martial Arts, 13(2), 44-63.

Paz-y-Miño C., G. \& Espinosa, A. (2004). Music principles applied to aikido techniques: Part II. Journal of Asian Martial Arts, 13(3), 64-81.

Plodowski, A. \& Jackson, S. (2001). Getting to grips with the Ebbinghaus illusion. Current Biology 11(8), R304-R306.

Reed, W. (1992). Ki: A road that anyone can walk, 2nd Ed. Tokyo: Japan Publications.

Reed, W. (1999). Ki: A practical guide for westerners, 6th Ed. Tokyo: Japan Publications.

Schlag, J. \& Schlag-Rey, M. (2002). Through the eye, slowly: Delays and localization errors in the visual system. Nature Reviews Neuroscience 3, 191-200.

Shifflett, C. (1998). Ki in aikido: A sampler of ki exercises. Merrifield, Virginia: Round Earth Publishing.

Shifflett, C. (1999). Aikido: Exercises for teaching and training. Merrifield Virginia: Round Earth Publishing.

Smeets, J., Brenner, E., De Grave, D. \& Cuipers, R. (2002). Illusions in action: Consequences of inconsistent processing of spatial attributes. Experimental Brain Research 147, 135-144.

Tohei, K. (1962). What is aikido. Tokyo: Rikugei Publishing House.

Tohei, K. (1974). This is aikido. Tokyo: Japan Publications.

Tohei, K. (2001). Ki in daily life. Tokyo: Ki No Kenkyukai Headquarters.

Tohei, K. (2001). The way to union with ki: Aikido with mind and body coordination, 1st Ed. Tochigi: Ki No Kenkyukai Headquarters.

\section{Agradecimientos}

Dedicamos este artículo a Mark Rubbert, William Reed, Koichi Kashiwaya, y Andrew Tsubaki, quienes nos han inspirado para explorar la fascinante complejidad del Shin Shin Toitsu Aikido (fundado por Koichi Tohei). Los contenidos que se tratan en este artículo no son suscritos necesariamente por la Sociedad Ki o por cualquiera de sus sociedades afiliadas 